\title{
Research on Construction and Evaluation Method of Comprehensive Evaluation Index System for Investment Benefit of Distribution Network
}

\author{
Ying $\mathrm{Li}^{1}$, Xueying Zhang ${ }^{1}$, Yue Zhang ${ }^{1}$, Laiyuan $\mathrm{Lai}^{2}$, Chao $\mathrm{Chen}^{3 *}$ \\ ${ }^{1}$ Guangdong Power Grid Co., Ltd., Guangzhou City, Guangdong Province 510000, China \\ ${ }^{2}$ Huizhou Power Supply Bureau, Guangdong Power Grid Co., Ltd., Huizhou City, Guangdong Province 516003, China \\ ${ }^{3}$ School of Economics and Management, North China Electric Power University, Beijing 102206, China
}

\begin{abstract}
Under the new situation, the improvement of investment efficiency and efficiency will be the basic criteria for evaluating the quality of power supply enterprises' investment activities in the distribution network. To this end, based on the characteristics of distribution network construction, combined with the internal and external development trends of power supply enterprises and development and promotion needs, this paper constructs a scientific comprehensive evaluation index system and evaluation method for the investment benefits of distribution networks, which is useful for scientifically grasping the investment needs and investment capabilities of power supply enterprises. It is of great significance to achieve a more precise and lean level of investment in the distribution network.
\end{abstract}

\section{Introduction}

At present, relevant scholars are very concerned about the benefit evaluation of power grid investment projects. Li Ming et al. ${ }^{[1]}$ built an evaluation index system and evaluation model for the whole process of power grid project investment based on variable weights to provide reference for power grid companies to carry out fixed asset investment evaluation. Ma Qian et al. ${ }^{[2]}$ established the investment ranking evaluation index system of power grid planning projects under the new power reform environment from the three dimensions of technology, benefit, and project maturity; then, the fuzzy analytic hierarchy process was used to obtain the weights of the above three indicators, and The comprehensive utility value of investment ranking is obtained based on the vector distance merging rule algorithm.

Liu Yinghan ${ }^{[3]}$ constructed the economic benefit evaluation index system of power grid investment projects from the dimension of financial benefit level. Dong Xiaojun et al. ${ }^{[4]}$ optimized the design of the implementation process for the post-evaluation of distribution network projects, and provided reference and reference for grid companies to improve the precise investment management of the distribution network.Wang Zheng ${ }^{[5]}$ constructed a comprehensive evaluation index of power grid investment benefits from four aspects: functional benefits, economic benefits, environmental benefits and social benefits, and constructed an evaluation and analysis model based on DEA theory.

\footnotetext{
*Corresponding author's e-mail: 1182306191@ncepu.edu.cn
}

In summary, the current research results involve the evaluation of power grid investment benefits, the evaluation dimension focuses more on the management of the whole process of project construction and the achievement of financial and economic benefits. The evaluation index system lacks a certain degree of systematicness and comprehensiveness. Therefore, it is necessary to study the comprehensive evaluation index system and evaluation method of the investment benefit of the distribution network.

\section{Analysis of influencing factors of distribution network investment demand}

\subsection{Index system construction and weight determination method}

This article combines the characteristics of distribution network investment projects, combined with the current situation and development needs of power grid enterprise distribution network investment management evaluation, after combing, summarizing, and refining many indicators involved in the process of power grid enterprise distribution network investment management, and at the same time, fully considering the indicators Factors such as the repeatability and correlation between indicators and the relationship between indicators and investment benefits have built a distribution network investment performance evaluation index system that 
includes four dimensions: reliable operation, clean and efficient, high-quality service, and benefit contribution.

Table 1. Comprehensive benefit evaluation index system of distribution network investment.

\begin{tabular}{|c|c|c|}
\hline $\begin{array}{c}\text { Serial } \\
\text { number }\end{array}$ & $\begin{array}{l}\text { Evaluation } \\
\text { dimension }\end{array}$ & Evaluation index \\
\hline 1 & \multirow{4}{*}{$\begin{array}{l}\text { Reliable } \\
\text { operation }\end{array}$} & $\mathrm{N}-1$ pass rate \\
\hline 2 & & $\begin{array}{l}\text { Proportion of heavy-duty } \\
\text { equipment in distribution network }\end{array}$ \\
\hline 3 & & Power supply reliability rate \\
\hline 4 & & $\begin{array}{l}\text { Comprehensive voltage } \\
\text { qualification rate }\end{array}$ \\
\hline 5 & \multirow{4}{*}{$\begin{array}{l}\text { Clean and } \\
\text { efficient }\end{array}$} & $\begin{array}{l}\text { Equivalent average load rate of the } \\
\text { whole network }(10 \mathrm{kV})\end{array}$ \\
\hline 6 & & $\begin{array}{l}\text { The proportion of light load } \\
\text { equipment }(10 \mathrm{kV})\end{array}$ \\
\hline 7 & & Line loss rate \\
\hline 8 & & Market share \\
\hline 9 & \multirow{3}{*}{$\begin{array}{l}\text { Quality } \\
\text { service }\end{array}$} & $\begin{array}{c}\text { Ten thousand households' voltage } \\
\text { quality complaints }\end{array}$ \\
\hline 10 & & $\begin{array}{c}\text { Number of complaints about power } \\
\text { outages in } 10,000 \text { households }\end{array}$ \\
\hline 11 & & $\begin{array}{l}\text { Comprehensive Industry Expansion } \\
\text { Index }\end{array}$ \\
\hline 12 & $\begin{array}{l}\text { Outstanding } \\
\text { performance }\end{array}$ & $\begin{array}{c}\text { Electricity sales per unit of grid } \\
\text { assets }\end{array}$ \\
\hline
\end{tabular}

In order to make the setting of indicator weights more reasonable and scientific, this article uses a combination of subjective weighting method and objective weighting method to set indicator weights. The specific index weight determination method is shown in Figure 1 below.

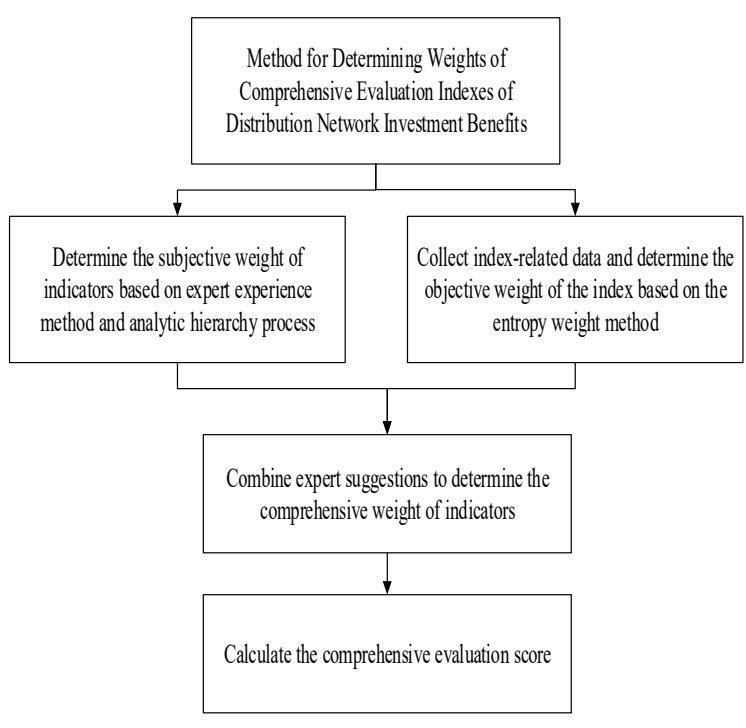

Figure 1. Evaluation index weight determination process.

\subsection{Matter element extension evaluation model}

The matter-element extension model is based on matter-element theory, extension set, correlation function and correlation degree. It is a method to quantitatively evaluate various indicators and systematically reflect the comprehensive evaluation results. The calculation steps of the matter-element extension model are as follows:

(1) Determine the matter element matrix of the classical domain. The matter-element matrix composed of thing $\mathrm{N}$, the characteristic $\mathrm{C}_{\mathrm{n}}$ of thing $\mathrm{N}$ and the standard range of the characteristic is the classical domain matter-element matrix, denoted as $\mathrm{R}_{\mathrm{j}}$, then there is:

$$
R_{j}=\left[\begin{array}{ccc} 
& c_{1} & \left(a_{j 1}, b_{j 1}\right) \\
& c_{2} & \left(a_{j 2}, b_{j 2}\right) \\
N_{j} & c_{3} & \left(a_{j 3}, b_{j 3}\right) \\
& \vdots & \vdots \\
& c_{n} & \left(a_{j n}, b_{j n}\right)
\end{array}\right]
$$

Among them, $N_{j}$ represents the $j-t h$ evaluation level $j$ of the target thing $N ; j=1,2, \ldots, m$ is the E-th evaluation index $\mathrm{F}$; $\mathrm{J}$ represents the value range of the index $\mathrm{K}$ in the level $\mathrm{H}$.

(2) Determine the node area matter element matrix. The matter-element matrix composed of thing $\mathrm{N}$, the characteristic $c_{n}$ of thing $\mathrm{N}$ and the extended range of the characteristic is the node-domain matter-element matrix, denoted as $R_{p}$, then there is:

$$
R_{p}=\left[\begin{array}{ccc} 
& c_{1} & \left(a_{p 1}, b_{p 1}\right) \\
& c_{2} & \left(a_{p 2}, b_{p 2}\right) \\
N_{p} & c_{3} & \left(a_{p 3}, b_{p 3}\right) \\
& \vdots & \vdots \\
& c_{n} & \left(a_{p n}, b_{p n}\right)
\end{array}\right]
$$

Among them, $N_{p}$ represents the overall evaluation level of things; $C_{i}$ is the $i$-th evaluation index $(i=1,2, \ldots, n) ; V_{p i}=\left(a_{p i}, b_{p i}\right)$ represents the value range of the index $i$ on the overall level, obviously $V_{p i} \subset V_{j i}$.

(3) Determine the element matrix to be measured.For a certain thing $N$ to be evaluated, the value of the $i$-th evaluation index $c_{i}$ is $v_{i}$, then the matrix to be measured is:

$$
R_{0}=\left[\begin{array}{ccc} 
& c_{1} & v_{1} \\
& c_{2} & v_{2} \\
& c_{3} & v_{3} \\
\vdots & \vdots \\
& c_{n} & v_{n}
\end{array}\right]
$$

(4) Find the degree of relevance according to the relevance function. The correlation function represents the extent to which the matter element meets the requirements when the value of the matter element is a point on the real axis. Correlation function is a transformation tool for quantitative changes of things, which can quantitatively express qualitative problems.

$$
K_{j}\left(v_{i}\right)=\left\{\begin{array}{cc}
-\frac{\rho\left(v_{t}, V_{j t}\right)}{\left|V_{j i}\right|} & v_{i} \in V_{j i} \\
\frac{\rho\left(v_{i}, V_{j i}\right)}{\rho\left(v_{i}, V_{p i}\right)-\rho\left(v_{i}, V_{j t}\right)} & v_{i} \notin V_{j i}
\end{array}\right.
$$

among them, 


$$
\begin{aligned}
& \rho\left(v_{i}, V_{j i}\right)=\left|v_{i}-\frac{a_{j i}+b_{j i}}{2}\right|-\frac{b_{j i}-a_{j i}}{2} \\
& \rho\left(v_{i}, V_{p i}\right)=\left|v_{i}-\frac{a_{p i}+b_{p i}}{2}\right|-\frac{b_{p i}-a_{p i}}{2} \\
& \left|V_{j i}\right|=\left(b_{j i}-a_{j i}\right)
\end{aligned}
$$

In the formula: $\rho\left(v_{i}, v_{j i}\right)$ represents the distance $v_{i}$ from each index value to the classical domain interval $V_{j i}, a_{j i}$ and $b_{j i}$ are the two end points of the interval respectively; $\rho\left(v_{i}, V_{p i}\right)$ represents the distance from the index value $v_{i}$ value to the node domain interval $V_{p i}, a_{p i}$ and $b_{p i}$ are the two endpoints of the interval; the calculation result $K_{j}\left(v_{i}\right)$ is the degree of association. The degree of relevance is similar to the degree of membership in fuzzy comprehensive evaluation. According to the criterion of maximum relevance:

$$
K_{j}\left(v_{i}\right)=\max K_{j}\left(v_{i}\right), j=1,2, \cdots, m
$$

Then the evaluation level of the identified index $c_{i}$ is $j$, and the formula $(5-44)$ can realize the evaluation and analysis of each index.Combining the correlation degree of each index with the index weight can get:

$$
K_{j}=\sum_{i=1}^{n} w_{i} K_{j}\left(v_{i}\right), \quad i=1,2, \cdots, n, \quad j=1,2, \cdots, m
$$

Among them: $w_{j}$ is the index weight, $K_{j}\left(v_{i}\right)$ is the correlation degree of the index $i$ on the $j$ level, $K_{j}$ is the correlation degree of the evaluation target, and the final comprehensive evaluation level is determined according to the formula (5) to realize the investment in the distribution network project Overall evaluation of benefits.

\section{Empirical analysis}

This paper takes my country's Z county-level power supply company's distribution network investment as an example to carry out empirical analysis and research. The basic data and scores are shown in Table 2 below:

Table 2. Basic data and evaluation score table.

\begin{tabular}{ccccc}
\hline $\begin{array}{c}\text { Evaluation } \\
\text { dimension }\end{array}$ & Evaluation index & $\begin{array}{c}\text { Index } \\
\text { value }\end{array}$ & Score & $\begin{array}{c}\text { Provincial } \\
\text { average } \\
\text { score }\end{array}$ \\
\hline $\begin{array}{c}\text { Reliable } \\
\text { operation }\end{array}$ & $\begin{array}{c}\text { N-1 pass rate } \\
\text { Proportion of } \\
\text { heavy-duty } \\
\text { equipment in } \\
\text { distribution network }\end{array}$ & $92.87 \%$ & 92.87 & 91.53 \\
\hline
\end{tabular}

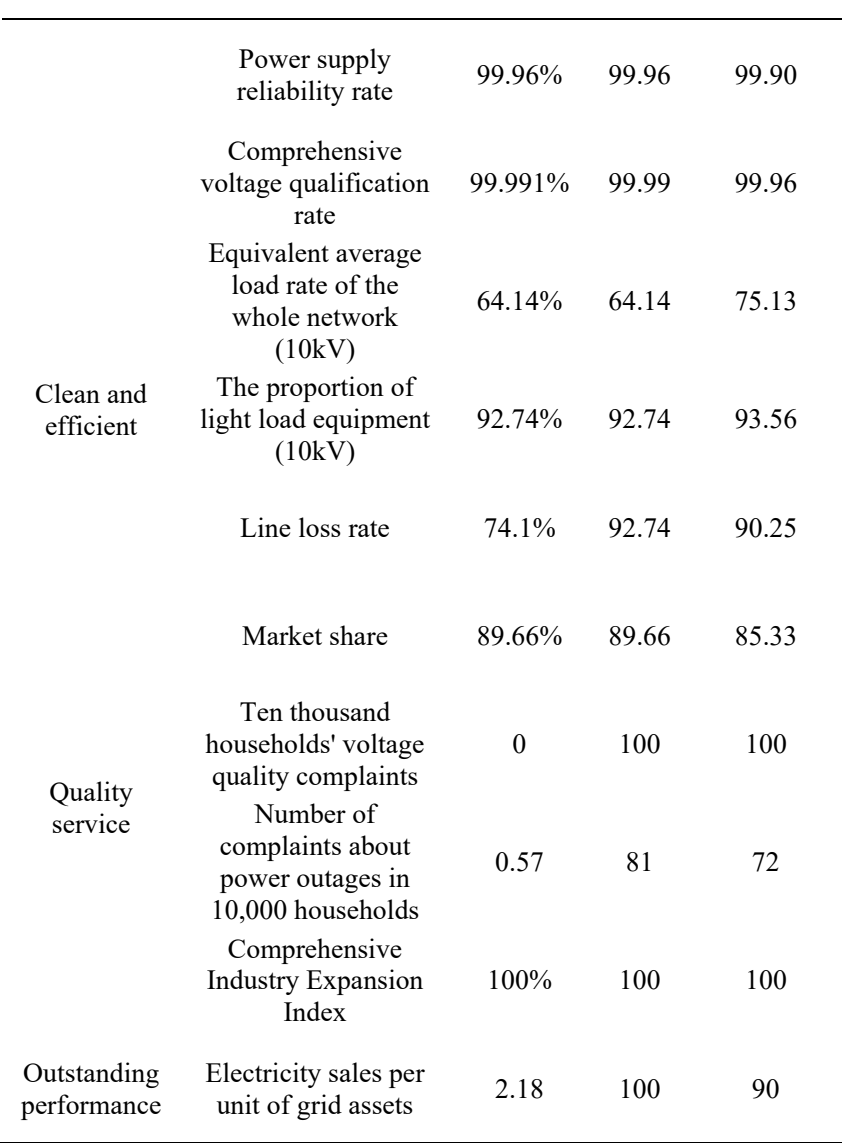

Through the evaluation, we can know: (1) Reliable operation. The N-1 pass rate, the proportion of heavy-duty equipment in the distribution network $(10 \mathrm{kV})$, the power supply reliability rate, and the comprehensive voltage qualification rate are all above the average level, and other indicators are below the average level. (2) Quality service. Except for tens of thousands of households with power outage complaints that scored below average, other indicators were above average. (3) Clean and efficient aspects. The indicator scores are all below average. (4) Significant aspects of performance. The indicator score is higher than average. Therefore, the future investment in the distribution network of County $\mathrm{Z}$ should focus on strengthening the safety and reliability of the distribution network and improving the efficiency of equipment utilization.

\section{Conclusion}

In order to further improve the investment benefit level of the distribution network, this article combines the investment characteristics and development needs of power grid enterprises to construct a comprehensive distribution network investment benefit based on multiple dimensions such as the development of the enterprise, the safe and reliable operation of the power grid, and the contribution of operating benefits Evaluation index system and evaluation methods. Through empirical analysis, the validity of the method model is verified. The research results can provide reference and reference for power grid companies to 
improve the investment efficiency of distribution network projects.

\section{References}

1. Li Ming, Tan Jieren, Kuang Shifang. Research on the whole process evaluation of power grid project investment based on variable weights[J]. Electric Power Survey and Design, 2020(12): 79-84.

2. Ma Qian, Wang Zhaocong, Pan Xueping, Liu Xiaofan. Evaluation method of power grid investment decision based on utility function under the environment of new power reform $[\mathrm{J}]$. Electric Power Automation Equipment, 2019, 39(12): 198-204.

3. Liu Yinghan. Application of economic benefit evaluation mechanism for power grid projects in investment decision-making [J]. China Management Information Technology, 2020, 23(17): 28-29.

4. Dong Xiaojun, Niu Sai. Process and method of post-evaluation of county-level distribution network projects[J]. Rural Power Management, 2019(10): $59-60$.

5. Wang Zheng. Research on Evaluation of Investment Benefit and Investment Decision of Power Grid Project Based on Super-efficient DEA [D]. North China Electric Power University (Beijing), 2018. 